\title{
NADIE HABLABA SINO DE POLÍTICA, MANIFESTACIONES Y DISCURSOS. UNA LECTURA DE PALOMITA BLANCA DE ENRIQUE LAFOURCADE, A PROPÓSITO DE LOS PORMENORES NARRATIVOS DEL RELATO
}

\author{
NO ONE USED TO SPEAK, UNLESS IT WAS ABOUT POLITICS, \\ DEMONSTRATIONS AND SPEECHES. AN ANALYSIS OF PALOMITA \\ BLANCA BY ENRIQUE LAFOURCADE, IN RELATION TO THE \\ NARRATION DETAILS OF THE STORY.
}

\author{
Pablo Fuentes Retamal \\ Investigador post doctoral Universidad de Concepción, Chile. \\ p.fuentes.retamal@gmail.com
}

\section{Resumen:}

Este artículo propone una lectura de Palomita blanca (1971) de Enrique Lafourcade, a partir del estudio de las "catálisis" o pormenores de la narración. Estas unidades mínimas establecen los puntos de anclaje que articulan el relato a nivel político, simbólico e ideológico. En detalles tan ínfimos como los nombres de los protagonistas, los colores que pintan sus ropas o los espacios que habitan, no sólo se hallan estrategias discursivas, sino que, además, indicios de un contexto histórico y social que subyace en los acontecimientos narrados. A partir de este ejercicio crítico establecemos diálogos intertextuales con aquellas otras novelas del autor cuyos argumentos se contextualizan en la década del setenta, vale decir, Salvador Allende (1973), Tres terroristas (1976) y Adiós al Führer (1982).

\section{Palabras clave:}

Literatura chilena; Enrique Lafourcade; Palomita blanca; catálisis; pormenores narrativos.

\begin{abstract}
:
This article suggests an interpretation of Palomita Blanca (1971) by Enrique Lafourcade from the study of the "catalyses" or narration details. These minor components establish anchor points that articulate the story at a political, symbolic and ideological level. In this way, in very negligible aspects such as the name of the protagonists, the colours of their clothes or the places where they live, we can not only find narrative strategies, but also hints of the historical and social context hidden in the narrated events. From this critical exercise we establish intertextual dialogues with those other novels written by the author, whose story lines are set in the seventies, that is to say, Salvador Allende (1973), Tres Terroristas (1976) and Adiós al Führer (1982).
\end{abstract}

\section{Keywords:}

Chilean Literature; Enrique Lafourcade; Palomita blanca; catalyses; narrative details. 


\section{Presentación}

Por todas partes están los poetas fijando, como en una gran fotografía, los detalles de la tierra, el rostro de Chile. Enrique Lafourcade, Animales literarios chilenos.

Palomita Blanca (1971), de Enrique Lafourcade ${ }^{1}$, es la novela chilena más vendida de todos los tiempos con más de setenta ediciones y millones de ejemplares comercializados (Aguirre 67). El argumento de este relato es sencillo, narra un amor juvenil entre:

Una adolescente pobre y un joven de buena familia, justo antes de que Salvador Allende sea elegido Presidente (...). El libro retrata el convulsionado Chile de los 70 - el incipiente hipismo, las peleas callejeras entre izquierdistas y derechistas, las diferencias sociales (...) la jerga juvenil como nadie lo había hecho antes en Chile. (Sierra 77)

A pesar del éxito que obtuvo Palomita blanca, escasos autores y críticos literarios han reconocido el valor artístico de esta novela. El escritor Alberto Fuguet rompe esta tendencia al señalar que devoró Palomita blanca en una tarde, relato que le abrumó y dejó "seriamente excitado" (312). El crítico Roberto Merino destaca la sagacidad de Enrique Lafourcade para sostener el universo narrativo con personajes básicos que revelan los conflictos seculares de nuestra sociedad (17).

Como adelantamos, un sector importante de la crítica literaria se conformó con subrayar el éxito editorial de Palomita blanca sin pretender averiguar cuáles son los factores estéticos y literarios que posibilitaron la notoriedad de esta novela. En este sentido, Cristián Gazmuri propone -con absoluta liviandad- que el único mérito de Palomita Blanca es ser "muy entretenida" (295). Bernardo Subercaseaux sigue esta

\footnotetext{
${ }^{1}$ La narrativa de Enrique Lafourcade se inscribe en la "Generación de 1950”, grupo literario cuyo nombre fue propuesto por el propio autor en su Antología del nuevo cuento en Chile (1954). Lafourcade precisa los rasgos escriturales que definen a este grupo literario, indicando que sus pares conciben el ejercicio literario como: hecho estético; son abiertamente, sensibles e inteligentes; antirrevolucionarios, pero vocacionalmente comprometidos; deshumanizados, en el sentido de Ortega y Gasset, y, aristocráticos y aislados (13 y ss.). De acuerdo con el crítico Óscar Galindo, los narradores más emblemáticos de esta generación son José Donoso, Jorge Edwards y el propio Lafourcade, autores que exploran en su narrativa la identidad santiaguina, sus personajes y paisajes urbanos (106).
} 
línea crítica, precisando que Palomita blanca es un relato insípido que tuvo un gran éxito editorial, debido al interés del público más que a su escaso valor literario (216).

Estos vacíos críticos nos invitan a estudiar Palomita blanca para averiguar cuáles son los recursos literarios que privilegió el narrador para cautivar a sus lectores. Seducción que se mantiene vigente ${ }^{2}$-a medio siglo de la publicación de esta novela- a pesar del complejo escenario político que contextualizan estas páginas, vale decir, los meses que antecedieron la elección del Presidente Salvador Allende, una época marcada por un clima de agitación permanente, a causa de la polarización ideológica ${ }^{3}$ que enfrentó a dos bandos irreconciliables de la sociedad (Milos 33).

Consideramos que las complejidades políticas y sociales que acontecieron en Chile durante la década del setenta son fundamentales en Palomita blanca, por consiguiente, el objetivo que acoge este artículo es identificar y analizar los recursos estéticos y literarios que privilegió el narrador de esta novela para representar esta contingencia política sin opacar el conflicto amoroso que sugieren las grandes acciones narrativas.

Nuestra propuesta de trabajo sugiere que los pormenores narrativos contienen los rasgos ideológicos, políticos y simbólicos que contextualizan la diégesis. En términos de Roland Barthes, las catálisis son las unidades narrativas responsables de articular los valores temáticos que sostienen el relato de Enrique Lafourcade.

Recordemos que Roland Barthes distingue, en El efecto de realidad (1968), dos unidades en la narración. Las denominadas "funciones cardinales" que constituyen las verdaderas bisagras del relato, y las "catálisis", que completan los espacios vacíos entre aquellas funciones primeras (179). A primera vista, pareciera que las catálisis no son más que detalles irrelevantes que sólo elevan el coste de la información narrativa, sin embargo, estas anotaciones son fundamentales, pues otorgan verosimilitud a la narración. El teórico francés cita un fragmento de Un corazón sencillo de Gustave Flaubert para demostrar la preponderancia de las catálisis; puntualmente, refiere aquel pasaje del relato que describe la sala de madame Aubain: "Un pequeño vestíbulo separaba la cocina de la sala donde madame Aubain se pasaba el día entero, sentada junto a la ventana en un sillón de paja (...). Un piano viejo soportaba, bajo un barómetro, una pirámide de cajas y cartones" (ctd. en Barthes 186). Aquel piano,

\footnotetext{
${ }^{2}$ La editorial Zig-zag publicó la septuagésima octava edición de Palomita blanca en abril de 2019.

${ }^{3}$ El historiador Pedro Milos señala que la sociedad chilena de la década del setenta estaba completamente polarizada: "la derecha, el centro y la izquierda representaban cada uno alrededor de un tercio del electorado, todos embarcados en posiciones políticas irreconciliables" (33).
} 
Artículo: Pablo Fuentes Retamal. "Nadie hablaba sino de política, manifestaciones y discursos. Una lectura de Palomita Blanca de Enrique Lafourcade, a propósito de los pormenores narrativos del relato".

barómetro, cajas y cartones no cumplen otra función más que señalar: "nosotros somos lo real" (Barthes 186). En síntesis, aquellos detalles, en apariencia inútiles, son aspectos de máxima consideración para el relato, pues aportan unidades de verosimilitud que denotan directamente lo real.

Michel Foucault también se refirió a la importancia de los detalles en Vigilar y castigar (1975). Este filósofo indica que la mecánica del poder concibe en los pormenores una acumulación de procesos minúsculos que convergen en beneficio de un diseño mayor (136). En este sentido, describir una microfísica implica atender detalles y minucias que, mediante un funcionamiento coherente y organizado, aportan sentido a lo ínfimo e insignificante.

La reflexión de Hayden White es el tercer pilar teórico que ilumina nuestra lectura crítica. Este filósofo revitalizó la conceptualización del discurso historiográfico al sugerir que una misma secuencia de acontecimientos se puede tramar de distintas maneras. De este modo, la narración histórica es el resultado de la sutileza del historiador en la elaboración de una trama específica para aquellos acontecimientos a los que adjudica "un tiempo especial de significado" (115). Esta conceptualización teórica establece vínculos profundos entre Historia y Literatura, evidenciando que los acontecimientos históricos se traman:

mediante la supresión y subordinación de algunos de ellos y el énfasis en otros, la caracterización, la repetición de motivos, la variación del tipo y el punto de vista, las estrategias descriptivas alternativas y similares; en suma, mediante todas las técnicas que normalmente esperaríamos encontrar en el tramado de una novela. (White 113)

De este modo, los sucesos que un relato histórico describe no cambian, sustancialmente, respecto de los acontecimientos que pormenorizan otros textos de la misma índole; más bien, lo que difiere son las modalidades y las relaciones que el historiador privilegia entre los hechos descritos (White 134). En otras palabras, lo que White pretende es evidenciar los fundamentos literarios sobre los que se construye el relato histórico.

Consideramos que nuestra propuesta crítica es inédita, pues no tenemos antecedentes de otro trabajo que estudie Palomita blanca. Además, estableceremos diálogos intertextuales entre esta novela y aquellos relatos de Enrique Lafourcade que 
también se enmarcan en el clima de agitación social acontecida en Chile durante la década del setenta, vale decir, Salvador Allende (1973), Tres terroristas (1976) y Adiós al Führer (1982). Este diálogo intertextual, además de enriquecer nuestra reflexión, trazará nuevas líneas de investigación que extienden el campo de los estudios literarios chilenos.

\section{Un análisis del pormenor narrativo en Palomita blanca}

...pedía que le volviéramos a describir todo, cada detalle. Detalles que nosotros mismos ignorábamos.

Enrique Lafourcade, Adiós al Führer.

Los apellidos de los protagonistas de Palomita blanca son antecedentes provechosos para nuestra lectura crítica, pues estos referentes nominativos no sólo contrastan el origen popular de "María Acevedo" (Lafourcade 37), respecto de la ascendencia burguesa de su pretendido, "Juan Carlos Eguirreizaga Montt" (Lafourcade 59); sino que, además, estos nombres evidencian algunas particularidades de la Ley de Filiación ${ }^{4}$ que estuvo vigente en los años setenta.

Esta normativa legal, establecida por el Código Civil de 1855, distinguió tres categorías para los niños nacidos en Chile: legítimos, ilegítimos y naturales ${ }^{5}$. La condición de ilegitimidad se aplicó a todos los menores concebidos fuera del matrimonio que no recibieron el reconocimiento paterno y también se adjudicó esta categoría a los niños cuyo progenitor impugnó legalmente la paternidad (Medina 416). La ilegitimidad fue una condición que prohibió heredar el apellido del padre, de modo que estos menores sólo recibieron el nombre materno, el cual se repetía en sus actas de nacimiento (Díaz 73). Esta condición filial explica la reiteración del apellido "Acevedo" para la protagonista de Palomita blanca, muchacha ilegítima que desconoce la identidad de su padre fallecido (Lafourcade 32$)^{6}$.

\footnotetext{
${ }^{4}$ La nueva Ley de Filiación chilena fue promulgada en 1998. Esta normativa legal puso fin a la discriminación vigente desde 1855, desde entonces, todos los niños que nacen en territorio nacional son iguales ante la ley.

${ }^{5}$ Los hijos naturales eran aquellos niños resultantes de la unión entre parejas de divorciados que, al momento de la concepción, no estaban unidos en matrimonio civil.

${ }^{6} \mathrm{La}$ orfandad es un motivo recurrente en la narrativa de Enrique Lafourcade, por ejemplo, la protagonista de Pepita de Oro (1989) vive con su madre y una empleada, pues, su padre, de quien no se revelan mayores antecedentes, se encuentra en viajes de negocios. Situación parecida ocurre en Mano bendita (1993) cuyo protagonista, el boxeador Evaristo Arce, custodia a su nieta enferma luego del abandono de sus padres biológicos.
} 
La Ley de Filiación fue especialmente cruel con los hijos ilegítimos, pues estos ciudadanos, de segunda categoría, sólo podían obtener el reconocimiento paterno tras interponer acciones judiciales; sin embargo, cuando un hijo ilegítimo conseguía el reconocimiento de su padre sólo se le otorgaba una manutención en alimentos, mientras que los derechos hereditarios continuaban absolutamente vedados (Díaz 73). En este contexto, la antropóloga Sonia Montesinos declara que el problema de la ilegitimidad atraviesa el orden social chileno, transformándose en una "marca" definitoria del sujeto en la historia nacional, un "estigma que continúa vigente en los códigos civiles" (50).

Los apellidos del joven protagonista de Palomita blanca, "Eguirreizaga Montt", también son significativos. Estos antecedentes nominativos anuncian su ascendencia vasca, prosapia que la investigadora Ainara Madariaga emparenta con los sectores más acomodados de la sociedad chilena:

Ser vasco en Chile es lo mismo que decir clase alta (...). Ser vasco en Chile, no es pasar inadvertido o estar relacionado o catalogado como de clase baja, sino todo lo contrario, lo vasco en Chile es la clase alta, lo ha sido históricamente y lo sigue siendo en la actualidad, de clase media-alta. (20)

Por consiguiente, los apellidos de los protagonistas de Palomita blanca, además de funciones nominativas, son antecedentes que evidencian las inequidades sociales que acontecieron en Chile. Mientras que un apellido de origen extranjero vincula a su portador con los segmentos más acomodados de la sociedad, la ilegitimidad es un infortunio que se reitera en cada oportunidad que un individuo precisa su nombre. En este sentido, siguiendo a Ronald Barthes, señalamos que las catálisis son aspectos de máxima importancia para el relato, unidades —en apariencias inútiles — pero capaces de articular los valores ideológicos que sostienen el relato.

Los primeros capítulos de Palomita blanca describen a María y a su amiga Telma mientras viajan a la periferia para participar en un festival de rock $^{7}$. Las ropas que visten las muchachas en esta instancia narrativa son interesantes para nuestra lectura crítica, pues evidencian las inequidades sociales que distinguen a los segmentos sociales descritos en el relato. De este modo, apuntamos que Telma viste un par de bluyins que despiertan las miradas lascivas de los varones: “con más éxito la tonta (...)

\footnotetext{
${ }^{7}$ Enrique Lafourcade se habría inspirado en el festival "Piedra Roja" para estructurar los primeros capítulos de Palomita blanca. Esta fiesta juvenil se desarrolló en el sector oriente de Santiago los días 10, 11 y 12 de octubre de 1970.
} 
como tiene esos bluyines nuevos que le quedan apretados y es media gorda de atrás, y se mueve entera al caminar" (Lafourcade 10). María, al igual que Telma, calza vaqueros. La protagonista refiere sus pantalones, a propósito de las vicisitudes que acontecieron durante la noche en este festival:

Me desperté cuando estaba saliendo el sol (...) sentí que me abrazaban y me besaban y trataron como de bajarme los pantalones, pero como andaba con esos bluyines bien ajustados que les dicen strech, y además con los pantis que me prestó la Telma. (Lafourcade 16)

Luego de revisar la historia de la moda, apuntamos que los "jeans" son un tipo de pantalones que fueron diseñados para fines laborales (Saulquin 38). Esta prenda se importó a Sudamérica desde los Estados Unidos, a partir de 1946, para vestir a los trabajadores de las estancias locales (Saulquin 44). A partir de estos antecedentes, proponemos que los bluyins que visten María y Telma constituyen pormenores narrativos que refuerzan el origen proletario de estas muchachas, ascendencia popular que comprueba la actividad laboral que ejerce Telma: “yo no sé dónde ha aprendido tanto, seguro que como trabaja de garzona en esa Fuente de Soda" (Lafourcade 10).

Un lector superficial podría pensar - equivocadamente- que el color azul que decora los pantalones de María y Telma es un detalle irrelevante en el relato. Por el contrario, esta elección cromática es de suma importancia, ya que este matiz refuerza el origen proletario de estas jovencitas. Con este propósito citamos aquel pasaje del relato que pormenoriza los pantalones azules de Telma: "tiene esos bluyines nuevos que le quedan apretados" (Lafourcade 10). María, al igual que su amiga, calza vaqueros azules: "el problema fue conseguirme ropa, porque no quería ir con los bluyines que estaban más viejos" (Lafourcade 101).

El color azul que tiñe los pantalones de estos personajes es un pormenor narrativo que nos compele a revisar la historia de la moda para comprender sus implicancias. Luego de satisfacer este requerimiento, indicamos que todos los vaqueros, en sus inicios, fueron tinturados con azul para camuflar la suciedad que se impregnaba en los pantalones de los obreros (Saulquin 17). A partir de esta observación, proponemos que los bluyines de María y Telma fueron coloreados con azul para reforzar el origen popular de estas muchachas. Esta estrategia narrativa nos remite a la reflexión teórica de Luz Aurora Pimentel, quien señala que los colores rebasan el simple 
Artículo: Pablo Fuentes Retamal. "Nadie hablaba sino de política, manifestaciones y discursos. Una lectura de Palomita Blanca de Enrique Lafourcade, a propósito de los pormenores narrativos del relato".

propósito de "pintar" una sección del relato, pues toda elección cromática conlleva un centro de imantación de los valores simbólicos e ideológicos que sugiere el relato (28).

A diferencia de los bluyines que visten María y Telma, Juan Carlos tiene a su disposición un nutrido ropero que no se restringe a una prenda ni a un color en particular. A modo de ejemplo, citamos un pasaje del relato que describe a este muchacho mientras se alista para visitar la playa: "volvió (...) con otros pantalones que eran amarillos con franjas naranjas" (Lafourcade 20). También referimos aquella escena de Palomita blanca que presenta a Juan Carlos con "pantalones, como de algodón blanco, bien finos se veían y tenía mocasines blancos también" (Lafourcade 109). Finalmente, referimos una escena que muestra cómo la ropa de Juan Carlos despierta la envidia de María: "llegó (...) con otros pantalones que seguro que debe de tener un montón, estos eran como morados y una camisa de encajes más linda, que ya me quisiera yo" (Lafourcade 58). El joven Eguirreizaga también dispone de accesorios para reforzar su origen burgués, por ejemplo, porta un lujoso reloj de pulsera: "yo le miré el reloj de oro que tenía Juan Carlos, y eran las once" (Lafourcade 25).

En definitiva, remitiéndonos a nuestro marco teórico, comprobamos que Michel Foucault está en lo correcto al sugerir que el poder hace presa en detalles mediante técnicas minuciosas para otorgar sentido a lo ínfimo e insignificante (136). Dispositivo que comprobamos luego de atender las implicancias de los bluyins que visten María y Telma, junto con las implicancias que conlleva el nutrido ropero de Juan Carlos. A fin de cuentas, estos pormenores narrativos son los responsables de articular los valores ideológicos que sostienen el relato.

Las catálisis que hemos analizado, hasta esta parte, muestran cómo el narrador de Palomita blanca dispone, en un primer plano del relato, el conflicto amoroso que convocan las grandes acciones del relato, mientras que la contingencia política y los enfrentamientos sociales que contextualiza la diégesis se despliegan en un telón de fondo. Este procedimiento narrativo permite a los lectores escoger la estrategia de lectura que mejor se acomode a sus intereses, vale decir, un ejercicio rápido y superficial que atienda el conflicto amoroso que convocan las "funciones cardinales" del relato, o bien, una lectura meticulosa que valore los conflictos sociales y políticos que contienen las "catálisis".

Las descripciones de los barrios que habitan los protagonistas de Palomita blanca aportan elementos significativos para nuestro ejercicio crítico. Recordemos la especificidad con que María puntualiza los alrededores de su domicilio: 
[Juan Carlos] me fue a dejar y a mí me daba harta vergüenza (...) por esas calles tan sucias que hay detrás de la Vega, y pa' más remate que yo vivía en la calle Salas al llegar a Lastra que es la más sucia de todas, con los camiones y las carretelas. (Lafourcade 37)

Luego de rastrear en el plano de Santiago la intersección que puntualiza la protagonista — calle Salas esquina Lastra- ubicamos el barrio Recoleta. Estas coordenadas urbanísticas son interesantes, pues añaden al relato un carácter histórico a merced de entidades semánticas estables. En palabras de Philippe Hamon, estos antecedentes funcionan a modo de citas pedagógicas que proyectan sobre la diégesis un "efecto de lo real que trasciende toda decodificación" (ctd. Pimentel 32).

Las menciones a las instalaciones del barrio Recoleta no son azarosas, por el contrario, este espacio urbanístico fue escogido, a causa de los antecedentes históricos que convoca. Este sector se emplaza en lo que se llamó, hasta 1945, "La Chimba", una zona cuyos orígenes se remontan al período colonial, época en que:

Los españoles producen una división de las tierras del valle de Santiago según el estatus que tuvieran sus habitantes (...). De este modo, los españoles de alto rango se situaron en torno a la Plaza de Armas, mientras que los de menor rango se establecieron al sur de la Alameda. Los indios, criollos pobres y yanaconas, en cambio, fueron ubicados en los sectores inundables, a orillas del Mapocho o en el área norte de la ciudad. De esta forma, La Chimba se configura —en especial durante el siglo XIX - en un lugar caracterizado por la emergencia de rancheríos y conventillos habitados por el bajo pueblo. (Vicencio 73)

Esta distribución urbanística marcó un hito en el devenir social de Santiago, pues esta fragmentación estableció una frontera humana ligada a "la precariedad, la criminalidad, la vagancia, la mendicidad, el alcoholismo, la prostitución y, en general, a todos los males vinculados con los sectores populares" (León 511). Estos flagelos sociales son referidos en Palomita blanca, a propósito de las impertinencias y groserías que profiere "El Milico", un vecino alcoholizado que acosa a las muchachas que circulan por este barrio:

\footnotetext{
${ }^{8}$ El historiador Marco Antonio León indica que el término "Chimba" proviene del quechua y significa "al otro lado del río" (511).
} 
Cuando iba a comprar el pan todos me gritaban cosas y uno me dijo: — ¡Dios le guarde las tetitas! Y me dio rabia, pero no le hice caso porque era un roto mugriento medio curado, "El Milico", que desde que llegué a Salas que me andaba molestando, y ni a la puerta del cité podía salir. (Lafourcade 40)

Enrique Lafourcade se refirió a los flagelos que azotan al barrio Recoleta, puntualmente el alcoholismo, en su novela Adiós Al Führer. Los párrafos finales de esta novela paródica ${ }^{9}$ describen a Joseph Goebbels bebiendo una copa de vino en una cantina del sector: "me interrogó luego Goebbels cuando comenzábamos con un jarro de chicha con naranjas en el Quitapenas ${ }^{10}$ de Recoleta" (Lafourcade Adiós 396).

En correspondencia con nuestro marco teórico, señalamos que las catálisis son recursos multifuncionales que otorgan verosimilitud a la narración (Barthes); además, estas unidades narrativas constituyen referentes lingüísticos que trazan puentes efectivos entre el mundo textual y el extratexto, permitiendo que el universo diegético entable relaciones intertextuales significativas con otros discursos, sean de índole, histórica, sociológica, urbanística, etc. (White).

Volviendo a Palomita blanca, indicamos que sus protagonistas particularizan sus respectivos establecimientos educacionales. A primera vista, estos antecedentes parecen datos irrelevantes, sin embargo, un lector minucioso valora esta información para comprender cómo opera el poder en el espacio diegético. Respecto de la escuela pública que educa a María, apuntamos el siguiente fragmento:

Juan Carlos me hablaba ahora. Una voz ronca y como lenta.

- ¿A qué colegio vas?

- Al Liceo número cuatro.

- ¿Y dónde está el Liceo número cuatro?

—En Recoleta. En Recoleta esquina Juárez. Ahí está. (Lafourcade 26)

Juan Carlos también distingue su casa de estudios. Es interesante que el protagonista se moleste luego de advertir que María desconoce su colegio, pues le parece inaudito que la muchacha no tenga antecedentes de esta institución bilingüe:

\footnotetext{
${ }^{9}$ El crítico Wellingtone Rojas se refiere al contenido paródico de esta novela con las siguientes palabras: "Adiós al Führer (...) no tiene alusiones históricas ni panegíricos ni tampoco una desmitificación del Führer, es más, ni siquiera cuestiona la potestad del tirano (...). No es una novela histórica; simplemente se trata de una parodia" (2).

10 Yael Zaliasnik se refiere a la historia del bar "Quitapenas" en Memoria inquieta (2016). Esta investigadora sostiene que esta cantina, ubicada en calle Recoleta, frente al Cementerio General de Santiago, tiene más de un siglo de existencia (108 y ss.).
} 
— ¿Tú estudias?

— Terminé. Es decir, termino este año... o sea, Humanidades...

— ¿Dónde?

- En el Saint George.

- ¿Y dónde queda el Saint George?

- ¡Chis, no sabes dónde queda el Saint George!

Me dio harta vergüenza haberle hecho esa pregunta, sobre todo porque me miró medio raro, pero no sabía. (Lafourcade 26)

Luego de revisar los registros escolares de Santiago confirmamos la existencia del "Liceo número cuatro de Recoleta" y del colegio "Saint George"11. De esta manera, siguiendo a Roland Barthes, proponemos que apuntar los nombres de estas instituciones educacionales es una estrategia narrativa que otorga verosimilitud a la narración. En este sentido, Luz Pimentel añade que "nombrar" es el recurso más simple y efectivo al momento de describir, pues otorgar a una entidad diegética el mismo nombre que ostenta otra en el "mundo real" remite al lector, sin ninguna mediación, a un espacio ya designado (37).

Los colegios puntualizados en Palomita blanca no sólo cumplen funciones nominativas, también muestran cómo opera el poder en la formación de las nuevas generaciones. De esta manera, la instrucción bilingüe de Juan Carlos justifica su preferencia por la música y la cultura anglosajona, mientras estos conocimientos idiomáticos permanecen vedados a María, pues no figuran en el plan de estudios que ofrece su escuela pública:

[Juan Carlos] me tomó una mano y me llevó por el salón y por una escalera hasta una pieza que era preciosa, llena de libros y de afiches (...) de los Beatles, y de otros cantantes.

— Este es Bob Dylan — me explicó.

- ¡Ah! - le dije.

— ¡Y este es Jimmy Hendrix! ¡El descueve!

Yo no conocía a nadie.

Y me mostró a otros, la Joan Báez y la Judy Collins, pero volvió a decirme que Hendrix era la muerte. (Lafourcade 34)

\footnotetext{
${ }^{11}$ El Liceo número cuatro de Recoleta se fundó en el año 1902 bajo la presidencia de don Germán Riesco, siendo Ministro de Educación don Rafael Balmaceda. A partir de 1919, este establecimiento educacional cambia su nombre a "Paula Jaraquemada". Esta denominación se mantiene hasta el día de hoy. A su vez, el colegio Saint George está ubicado en el sector oriente de Santiago. Este establecimiento bilingüe, fundado en 1936, es conducido por la Congregación de la Santa Cruz. Actualmente, este colegio ejerce una importante labor de socialización para los hijos de las elites (Joignant 230).
} 
Artículo: Pablo Fuentes Retamal. "Nadie hablaba sino de política, manifestaciones y discursos. Una lectura de Palomita Blanca de Enrique Lafourcade, a propósito de los pormenores narrativos del relato".

La educación bilingüe a la que accede Juan Carlos justifica los versos que le dedica a María, composiciones escritas en inglés que parafrasean una canción del grupo británico The Beatles: “él me escribió en un papelito (...) era algo como: «one day, you'll find that I'll be gone» ${ }^{12}$ " (Lafourcade 37). María recibe con extrañeza esta dedicatoria, pues su desconocimiento idiomático le impide valorar el contenido de este mensaje. Esta incomprensión lingüística justifica la preferencia de esta muchacha por las canciones cuyas letras fueron compuestas en español: "puse la radio a ver si encontraba algo de [Armando] Manzanero que me gusta tanto" (Lafourcade 31). Algunas páginas más adelante, María reitera este interés musical:

Yo corría a encerrarme a mi pieza y ponía la radio a ver si salía [Armando] Manzanero y una vez escuché cuando cantó eso de "esa tarde vi llover", y se me saltaron las lágrimas, y aunque no llovía, aunque estaba bien nublado, de todos modos, cuando decía "y no estabas tú" yo me imaginaba a Juan Carlos. (Lafourcade 40)

Siguiendo la reflexión de Michel Foucault, señalamos que la referencia al cantante "Armando Manzanero" es un indicio textual que evidencian cómo opera el poder en el espacio diegético. Esta anotación nos trae a la memoria una de las estrategias de control que dispuso la dictadura de Augusto Pinochet para distraer la atención de los chilenos mientras el régimen militar cometía barbaridades contra sus opositores. En este sentido, la investigadora María Olivia Mönckeberg indica que la dictadura se valió de algunos espectáculos artísticos para apaciguar el ánimo de la población, por ejemplo, la presentación del cantante mexicano Armando Manzanero distrajo a los chilenos "con sus románticas canciones — «Esta noche vi llover, vi gente correr y no estabas tú...»— en el Hotel Carrera, a pocos pasos de La Moneda bombardeada" (222).

La presencia del poder se comprueba en otro episodio de Palomita blanca, nos referimos a aquel pasaje del relato que pormenoriza a María mientras observa la televisión en compañía de sus amigas. En esta escena es importante considerar que las muchachas sintonizan el programa "Sábados Alegres": "yo sabía bailar algo, porque

\footnotetext{
${ }^{12}$ Este dedicatoria fue parafraseada, a partir de un verso de la canción I'll Follow the Sun escrita por Paul McCartney. La composición original de este verso señala lo siguiente: "one day you'll find / that I have gone".
} 
con la Mirta habíamos practicado, y en la casa de la Mirta tenían televisión y a veces veíamos unos festivales y los Sábados Alegres” (Lafourcade 101).

Recordemos que "Sábados Alegres""13 fue un programa televisivo cuya popularidad se explica en el marco de las restricciones que impuso la dictadura militar, sumado a la precaria situación económica que azotaba a

una parte importante de la población y las restricciones que el régimen impuso a la vida política, social y cultural del país. (...) Este programa y otros de su estilo (...) satisficieron, efectivamente, las necesidades populares de representación, participación y beneficencia, compensando la falta de otras instancias para ello. (Durán 52)

El escritor Rafael Gumucio explica el rol que desempeñó el programa "Sábados Alegres", y su sucesor, "Sábados Gigantes", en el quehacer íntimo de las familias chilenas:

[Sábados Alegres] existía antes de la dictadura, pero durante ella sólo existió Sábados Gigantes. Y, de pronto, mientras la vida se hacía gris y negra, la pantalla empezó a tener colores. (...) ¿Cómo querían que prefiriéramos una verdad horrible a una ficción, la de Don Francisco ${ }^{14}$ ? (...) El televisor quedó encendido en el fondo de la casa como el ancla que mantiene a los barcos sujetos al fondo de coral. (143)

Desde la mirada que propicia nuestro marco teórico, proponemos que el programa "Sábados Alegres" constituye un pormenor narrativo que evidencia una de las estrategias de resistencia que desplegaron las familias chilenas para resistir las barbaridades que perpetró la dictadura. En este sentido, siguiendo a Michel Foucault, comprobamos que, efectivamente, el poder hace presa en detalles. De la misma manera, señalamos junto a Hayden White que la mención al programa "Sábados Alegres" es una estrategia narrativa que visibiliza los contenidos históricos que permanecen soterrados en el texto literario.

\footnotetext{
13 “Sábado Alegres" se emitió, por primera vez, en abril de 1963. Debido a su popularidad, este espacio televisivo cambió su nombre, en 1965, a "Sábados Gigantes". Este show se mantuvo vigente, ininterrumpidamente, hasta septiembre de 2015.

${ }^{14}$ Se refiere a Mario Kreutzberger, presentador de este show televisivo.
} 
Artículo: Pablo Fuentes Retamal. "Nadie hablaba sino de política, manifestaciones y discursos. Una lectura de Palomita Blanca de Enrique Lafourcade, a propósito de los pormenores narrativos del relato".

Los capítulos finales de Palomita blanca describen, de manera evidente, la polarización política que afectó a la sociedad chilena en el marco de las elecciones presidenciales de 1970. Tres candidatos se disputaron el sillón presidencial en aquella oportunidad: Arturo Alessandri, candidato de la derecha, de los partidos Liberal y Conservador; Radomiro Tomic, candidato de centro, representante de la Democracia Cristiana; y, Salvador Allende, candidato de los sectores de izquierdas (Milos 45). Este complejo panorama político se retrata en Palomita blanca, a propósito de un debate político que María presencia:

Vimos cómo eran los tres candidatos, y el más dije era Alessandri, como buenmozo era el viejo y medio enojado todo el tiempo (...) Allende era como con cara de profesor, se parecía al señor de física que teníamos, un viejo con el mismo bigote así medio blanco (...) y el otro, Tomic era muy negro con anteojos y el pelo blanco, todos tenían anteojos, y Tomic se parecía a un cura (...) hablaba así como los curas como perdonándolos a todos. (Lafourcade 44)

Luego de revisar el trabajo del historiador Pedro Milos, Chile 1970: El país en que triunfa Salvador Allende (2003), comprobamos que María está en lo correcto al señalar que dicha contienda electoral estuvo marcada por la disputa que sostuvieron Arturo Alessandri y Salvador Allende: “en el colegio todos andaban en lo mismo y en todas partes (...) me puse a mirar y todo Santiago estaba lleno de letreros y la cosa era entre Alessandri y Allende" (Lafourcade 43). Es interesante destacar el compromiso político que mostraron los electores chilenos de aquellos entonces, pues, tal como indica Jorge Baradit, "la gente opinaba en las calles de manera abierta y coherente sobre política. Todos querían participar, para avanzar o frenar lo que fuera, pero nadie era indiferente" (17). Este compromiso con el quehacer ciudadano encuentra un correlato en Palomita blanca, puntualmente, en las palabras de la protagonista: "estábamos como a fines de agosto y nadie hablaba sino de política, de manifestaciones, y la radio puros discursos" (Lafourcade 56).

María y Juan Carlos, a pesar de su corta edad, no son indiferentes al complejo escenario político que atraviesa el país, por el contrario, estos jovencitos definen sus posiciones ideológicas y manifiestan sus preferencias políticas. De este modo, nos enteramos que María es partidaria de Salvador Allende: “yo (...) me puse más allendista y pasábamos discutiendo con otras compañeras del Cuarto B” (Lafourcade 43). Algunos 
párrafos más adelante, esta muchacha reitera su compromiso con el líder de la Unidad Popular:

Yo le dije a la Telma que yo era Allendista la Telma se puso a reír y me dijo que qué cresta me podía importar, y yo le dije que me importaba porque mi mamá estaba metida en el barro hasta el cogote que tenía nueve hermanitos que se morían de hambre. (Lafourcade 44)

Juan Carlos también define su identidad política. A diferencia de María, este joven comparte afinidad con las promesas electorales de Arturo Alessandri, candidato que defiende los intereses del sector conservador:

— ¿Por quién vai a votar?

(...) ¿Quién te gusta?

(...) seguro que él era alessandrista, porque la Mirta Soto me había dicho que era un momio ${ }^{15}$, así que le dije:

— Mira, no sé... No me he decidido...

(...)

— Va a ganar Alessandri —me dijo. (Lafourcade 59)

Los protagonistas de Palomita blanca, además de definir sus posiciones políticas, participan en manifestaciones de apoyo a sus respectivos candidatos. De este modo, nos enteramos que María integra la columna de pobladores que desfilan por las calles de Santiago en apoyo al candidato Salvador Allende: "don Beno iba a la cabeza de la columna (...) y comenzaron a caminar y a gritar, y todos gritábamos: ¡Allende! ¡Allende! ¡Allende no se vende!...” (Lafourcade 45).

En este punto es necesario hacer una pausa para enfocarnos en los colores que "pintan" a María en esta parte del relato. Como ya dijimos, la protagonista fue coloreada con "azul" en la primera parte de Palomita blanca, sin embargo, los capítulos finales de esta novela describen a María coloreada de "rojo". Esta variante cromática se suscita una vez que la protagonista declara su apoyo a Salvador Allende y participa, activamente, en las concentraciones a favor de esta candidatura:

\footnotetext{
15 "Momio" es un neologismo usado en Chile para designar a los partidarios de los sectores de derecha. Este término, de uso frecuente durante el gobierno de la Unidad Popular, deriva de la palabra "momia". Concepto que se refiere la mentalidad estática y permanente de quienes defienden las ideas conservadoras (Joignant 181).
} 
me puse los pantalones, (...) y una chomba de jersey roja, la más bonita de todas, que me regaló mi madrina el año pasado para mi cumpleaños y como soy bien morena dicen que el rojo me queda muy bien. (Lafourcade 49)

El color rojo que decora el jersey de María es un detalle que rebasa el simple propósito de pintar una sección puntual del relato. Luego de realizar una lectura política de este color proponemos que esta tonalidad fue escogida por los Partidos Socialistas y Laboristas para representar la Segunda Internacional; además se proclamó, en 1918, que el color rojo sería el símbolo de la Unión de Repúblicas Socialistas Soviéticas y de las banderas de los Partidos Comunistas del mundo. En este sentido, Pablo Soler indica que el rojo es "el color de la rebelión” (26).

Enrique Lafourcade se refirió a las implicancias políticas del color rojo en la novela Salvador Allende (1973). Este relato recrea las últimas horas del Presidente Allende mediante un monólogo interior que repasa la biografía del mandatario. Durante esta instancia narrativa el protagonista rememora algunos pasajes de la vida de su abuelo paterno, Ramón Allende Padín ${ }^{16}$, político chileno al que sus detractores apodaron "el rojo", a causa de sus ideas libertarias (Lafourcade Allende 35).

El investigador Gunther Wessel declara que existen dos motivos para justificar el apodo del abuelo de Salvador Allende, por una parte, "sus concepciones políticas radicales, pero, por otro lado, (...) su llamativo pelo rojo" (32). Al menos, en la novela de Enrique Lafourcade, nos queda claro que el apodo de Ramón Allende Padín se debe a sus ideas revolucionarias:

Mi abuelo quería reglamentar la prostitución, tú sabes empadronar a las putas y controlarlas médicamente, ¡imagínate, esto, a fines del siglo pasado!, lo querían linchar, pidieron su cabeza, sus barbas, lo querían matar porque luchó por imponer la vacuna obligatoria vacuna para todos, los niños temblaban de miedo al verle en la calle, era el vacunador, el que hacía sufrir, Ramón el Rojo, el hereje, el que no tenía derecho a comunión. (Lafourcade Allende 41)

\footnotetext{
16 Jorge Arrate indica que Ramón Allende Padín (1845-1884) fue un "médico, diputado y senador, descollante figura del Partido Radical en la segunda mitad del siglo XIX (...) conocido como "el Rojo" por su anticlericalismo y su audaz pensamiento liberal, fue excomulgado de la Iglesia Católica y alcanzó el más alto grado en las logias masónicas" (13).
} 
Volviendo a Palomita blanca, indicamos que María forja vínculos con personajes afines a su identidad política. De esta manera, nos enteramos de la existencia de René, un militante de las Juventudes Comunistas que no desaprovecha ninguna ocasión para cortejar a la protagonista:

yo fui a dos concentraciones más (...) y en la segunda un joven que llevaba una bandera chilena como que me anduvo siguiendo, porque se instaló a mi lado y no se me despegaba, más lingote, y me dijo que le ayudara a sostener la bandera chilena, y cada vez que nos poníamos a gritar, me miraba a los ojos, como si estuviéramos cantando a dos voces, y me dijo que él era de las Juventudes Comunistas y me dijo que yo tenía unos ojos verdes preciosos. (Lafourcade 57).

Este flirteo se reitera algunos párrafos más adelante, a razón de la invitación que René extiende a la protagonista para celebrar juntos el triunfo de la Unidad Popular: "el joven de la bandera volvió a aparecer y me dijo que cómo me llamaba y yo le dije que María, él se llamaba René y me dijo que íbamos a celebrar el triunfo juntos" (Lafourcade 58).

Otras novelas de Enrique Lafourcade también muestran un desfile de militantes comunistas en sus páginas, por ejemplo, la protagonista de Tres terroristas $^{17}$ (1976) se presenta a los lectores con las siguientes palabras:

—Beatriz Cárdenas Hernández, 19 años, soltera alias "La Roja", alias "Rosa Luxemburgo", alias "La Luxemburgo", comunista, chilena, ¿qué más? (...) Soy...soy... bueno, de las jota-jota-cece, ¿sabes? De las Juventudes Comunistas de Chile. (Lafourcade Terroristas 52)

Esta joven comunista, al igual que María en Palomita blanca, viste prendas de color rojo: "Beatriz deslumbraba a sus compañeros con sus botas de cabritilla roja" (Lafourcade Terroristas 161). El matiz que decora la casa de esta militante comunista

\footnotetext{
${ }^{17}$ El crítico Hugo Montes resume el argumento de Tres terroristas, indicando que sus protagonistas son: "una joven provinciana (...) un muchacho, hijo de acaudalados venezolanos, (...) un ex seminarista uruguayo" (3). Estos personajes "cometieron cuanto atentado puede imaginarse. Torturaron y fueron torturados, mataron u ordenaron dar muerte, dijeron incendiarios discursos, fueron de país en país y hasta de continente en continente... pero están encerrados en una Embajada, y todo se les vuelve recuerdo que en gran parte es pesadilla". (Montes 3)
} 
dialoga con su identidad política: "—mi casa (...) es de una madera roja, alerce puro" (Lafourcade Terroristas 14).

Volviendo a Palomita Blanca, señalamos que Juan Carlos, al igual que María, forja vínculos con personajes afines a su identidad política, en este caso su hermano José Luis milita en una agrupación católico-conservadora: "mis hermanos, bueno, el José Luis, (...) es de Fiducia" (Lafourcade 59). Aunque la relación de Juan Carlos con su hermano mayor es compleja, desde nuestra perspectiva de estudio es interesante destacar la mención a la agrupación Fiducia, sector conservador cuyos fundamentos ideológicos postularon la reivindicación de

una estética formal (...) defendían los estrictos dogmas de la Iglesia Católica, esto es, eran contrarios al divorcio, al control de la natalidad y predicaban una fe que una vez impuesta, significaría orden y no desorden, sacrificio y no agrado, jerarquía y no igualdad. (Valdivia 136)

A comienzos de la década del setenta, la agrupación Fiducia cuestionó los cambios revolucionarios que anunció la Unidad Popular. De este modo, todos los esfuerzos de esta organización conservadora se enfocaron en la defensa de "las tradiciones y de la sociedad señorial" (Valdivia 137).

Vincular a María con las Juventudes Comunistas y a Juan Carlos con el Fiducia es una estrategia narrativa que evidencia las disparidades existentes entre los sectores políticos que representan estos personajes. Probablemente, un lector superficial no advierta la relevancia de estos antecedentes descriptivos, por este motivo recomendamos una lectura pausada y reflexiva que valore las catálisis del relato para, así, acceder a un nivel profundo de comprensión textual.

El último capítulo de Palomita blanca describe a María mientras escucha el noticiero radial para conocer los antecedentes del asesinato del General René Schneider ${ }^{18}$ :

\footnotetext{
${ }^{18}$ El jueves 22 de octubre de 1970 el General René Schneider fue emboscado por varios vehículos. Un grupo de jóvenes rodeó el automóvil en que se desplazaba el General, destrozando con martillos los cristales y la puerta lateral derecha. Los secuestradores, al percatarse que el militar repelía el ataque con su arma de servicio, dispararon sobre el uniformado impactándolo en tres ocasiones. Estas heridas balísticas le quitaron la vida al General Schneider, quien falleció en el Hospital Militar la madrugada del domingo 25 de octubre de 1970.
} 
Y entonces escuché la radio (...) cosas terribles, que habían baleado al General Schneider, que era el General en Jefe del Ejército, que lo habían encerrado entre varios autos y lo balearon (...) que estaba muy grave, decían, que era un atentado político, que lo habían llevado al Hospital Militar, que si no es por el chofer del auto que corrió al Hospital, que el Presidente Frei, que el Intendente, que Allende, que iban a declarar estado de sitio en Santiago, y seguían y seguían las noticias, las declaraciones. (Lafourcade 141)

De acuerdo con la investigación de Patricia Politzer, el asesinato del General Schneider fue planificado y ejecutado por miembros de "Patria y Libertad", un movimiento paramilitar de ultraderecha que rechazó la política no deliberante que ordenó este Comandante en Jefe del Ejército (112). Recordemos que el General René Schneider dictó a sus subalternos el siguiente mandato:

Hemos aceptado el veredicto de las urnas. Reconocemos y apoyamos en estos momentos a dos postulantes a la Presidencia de la República, que son los que obtuvieron las dos primeras mayorías relativas, el señor Allende y el señor Alessandri. Legalmente le corresponde al Congreso Nacional decidir cuál de los dos será el futuro Presidente de Chile, y a quien elijan ahí, lo debemos apoyar hasta las últimas consecuencias. (Ctd. Fuentes 140)

El General René Schneider quiso garantizar al pueblo chileno que el Ejército acataría el resultado eleccionario de 1970, haciendo efectivo el principio de prescindencia política que ordena la Constitución al mundo castrense (Valdivia 187).

El asesinato del General Schneider es un acontecimiento importante en Palomita blanca, lo que explica el asombro de María luego de revisar los periódicos y enterarse que Juan Carlos participó en el comando paramilitar que asesinó a este militar:

Me mostró el diario, y después me mostró otros y vi la foto de Juan Carlos en todas partes, de pie, de frente, con sus padres, con sus hermanos, y le decían cosas terribles: "momio asesino" (...) y decían que estaba preso, (...) que lo habían llevado a declarar. (Lafourcade 147-8) 
Artículo: Pablo Fuentes Retamal. "Nadie hablaba sino de política, manifestaciones y discursos. Una lectura de Palomita Blanca de Enrique Lafourcade, a propósito de los pormenores narrativos del relato".

Esta escena es provechosa para nuestra lectura crítica, pues los periódicos que consulta María convocan significados históricos que es necesario atender: "Iba todos los días a la casa de la Mirta a leer los diarios que ella compra "El Siglo" y otro que se llama "Puro Chile" y allí venían montones de nombres con fotos (...) había como cien detenidos" (Lafourcade 143). Debemos recordar que en las primeras páginas de Palomita blanca se presentó a la protagonista consultando El Clarín: "Todo comenzó cuando con la Telma decidimos ir al Festival. Habíamos leído en "El Clarín" que el Festival era allá arriba, en el barrio alto" (Lafourcade 7). En definitiva, los periódicos que María consulta son: El Siglo, Puro Chile y El Clarín.

Esta triada informativa es interesante, pues estos periódicos fueron decisivos en la candidatura de Salvador Allende y, más tarde, en el gobierno de la Unidad Popular. Por consiguiente, los periódicos que María revisa constituyen pormenores narrativos que dialogan con la identidad política de esta muchacha, detalles que parecen irrelevantes, en un primer nivel de lectura, pero que articulan los valores ideológicos que sostienen el relato.

Luego de revisar algunos antecedentes sobre estos periódicos para conocer su legado y proyección informativa nos enteramos que estos matutinos fueron sacados de circulación durante la dictadura de Pinochet, a causa del allanamiento y destrucción de las imprentas que los editaban. La periodista Claudia Lagos comenta que "los talleres de la Empresa Horizonte, donde se imprimían, El Siglo y Puro Chile (...) fueron desmantelados completamente. Lo mismo ocurrió con El Clarín y su oficina, que terminó convertida en el cuartel de tortura apodado La Firma" (58).

Estos antecedentes históricos demuestran la validez de la propuesta teórica de Hayden White, efectivamente, el texto literario tiene las competencias necesarias para convocar en sus páginas ciertos contenidos históricos, en el caso de Palomita blanca, los pormenores narrativos del relato son las unidades encargadas de convocar los contenidos históricos que el autor pretende visibilizar. 


\title{
Comentarios finales y proyecciones
}

\author{
Yo me moriré y seguirá saliendo... la Paloma seguirá volando. ${ }^{19}$ \\ Enrique Lafourcade.
}

La crítica literaria ha prestado más atención al éxito comercial de Palomita blanca que a los factores estéticos y literarios que explican la notoriedad de esta novela. Hasta ahora, ninguna lectura crítica se había preguntado cuáles son los recursos literarios que posibilitan la identificación de los lectores nacionales con este relato, valoración que se mantiene vigente, a pesar del complejo escenario político que contextualizan estas páginas, vale decir, una época convulsionada que pone en discusión temáticas conflictivas que aún dividen a los chilenos.

Nuestra lectura crítica sugiere que Palomita blanca ofrece dos posibilidades de lectura. En primer orden, un ejercicio rápido y superficial que sólo atienda las grandes acciones narrativas, por otro lado, un ejercicio meticuloso y reflexivo que valore los pormenores del relato. Ambas posibilidades son válidas, sin embargo, aquellos lectores que privilegien un ejercicio pausado y atienden las catálisis del relato, acceden a una comprensión textual profunda que despliega la contingencia político-social de los años setenta.

Los niveles de lectura que ofrece Palomita Blanca nos remiten a las palabras que expresó Roberto Bolaño al escritor Pedro Lemebel en una entrevista radial. En aquella oportunidad el autor de Los detectives salvajes indicó que "todos los libros son difíciles en cierto nivel de lectura, pero, sólo los buenos libros, son fáciles en un primer nivel de lectura" (1999).

Si damos por correcta esta afirmación, las palabras de Bolaño nos sirven para discutir con Cristian Gazmuri y Bernardo Subercaseaux, quienes, como ya dijimos, niegan el valor literario de Palomita blanca, señalando que el único mérito de esta novela es de carácter comercial, en ningún caso, de índole literaria.

El estudio de las catálisis de Paloma blanca nos permitió demostrar el sustrato político que fundamenta este relato. Una novela que consigue visibilizar las confrontaciones sociales que acontecieron en Chile mediante la descripción de aspectos tan ínfimos como los apellidos de los protagonistas, las ropas que visten los personajes, los espacios en que se desarrollan las acciones, entre otros aspectos; a fin de cuentas,

19 Enrique Lafourcade pronunció esta frase en una entrevista que concedió a la periodista Anuschka Bannach Canales (1993). 
Artículo: Pablo Fuentes Retamal. "Nadie hablaba sino de política, manifestaciones y discursos. Una lectura de Palomita Blanca de Enrique Lafourcade, a propósito de los pormenores narrativos del relato".

elementos constitutivos del relato que, hasta ahora, permanecían en competo desconocimiento.

Si tuviésemos que referir algunas palabras para explicar el éxito editorial de Palomita blanca señalaríamos que esta novela no pretende reflejar especularmente la sociedad chilena de 1970, sino que, más bien, retratar los imaginarios sociales y sus efectos, a propósito de una sencilla historia de amor juvenil. En otras palabras, el romance que sostienen María y Juan Carlos en la ficción novelesca no es más que un pretexto para describir el acontecer político de una época convulsionada.

Para finalizar, nos parece interesante acoger la propuesta de la escritora Diamela Eltit, quien sugiere que La parrilla (1980), novela testimonial de Adolfo Pardo, es un relato que continúa el hilo narrativo propuesto en Palomita blanca. De este modo, La parrilla fundaría una saga que, en palabras de Eltit, se precipita después "del Golpe de 1973, entonces, la Paloma fue capturada para ser arrastrada al centro mismo de la pesadilla" (6). En este sentido, consideramos provechoso extender los parámetros reflexivos que propone este artículo y establecer un ejercicio comparativo entre la narrativa de Enrique Lafourcade y la escritura Adolfo Pardo. Tal vez, esta lectura crítica podría revelar ciertos vínculos significativos entre estos programas escriturales cuyos puntos de encuentro permanecen, hoy, en absoluto desconocimiento.

\section{Bibliografías}

Aguirre, Mariano. Razones de un lector. Veinte años de crítica literaria. Santiago, Chile: Ril, 2010.

Arrate, Jorge. Salvador Allende ¿Sueño o proyecto? Santiago, Chile: Lom, 2008.

Bannach, Anuschka. "Hay Paloma para rato". La Tercera (Santiago, Chile), 5 Feb. 1993: 3.

Baradit, Jorge. La dictadura. Historia secreta de Chile. Santiago, Chile: Penguin Random House Grupo Editorial, 2018.

Barthes, Ronald. "El efecto de realidad". El susurro del lenguaje. Más allá de la palabra y la escritura. Madrid: Paidós, 1987. 179-187.

Díaz, José. "Nacimientos fuera del matrimonio en la historia de chile: algunos hechos estilizados". Estudios Públicos 142 (2016): 37-79.

Durán, Sergio. Ríe cuando todos estén tristes. El entretenimiento televisivo bajo la dictadura de Pinochet. Santiago, Chile: Lom, 2012.

Eltit, Diamela. "Bitácora de una infamia". La parrilla. Santiago, Chile: Ocho libros, 2012. 3-9.

Foucault, Michel. Vigilar y castigar. Nacimiento de la prisión. Buenos Aires, Argentina: Siglo veintiuno, 2002. 
Fuentes, Manuel. Memorias secretas de Patria y Libertad. Santiago, Chile: Grijalbo, 1999.

Fuguet, Alberto. Apuntes autistas. Santiago, Chile: Aguilar, 2007.

Galindo, Óscar. "Metatextos e imaginarios identitarios en la literatura chilena (19501970"). Estudios filológicos 43 (2008): 101-114.

Gazmuri, Cristián. Historia de Chile: 1891-1194. Política, economía, sociedad, cultura, vida privada, episodios. Santiago, Chile: Ril, 2012.

Gumucio, Rafael. Los platos rotos. Historia personal de Chile. Santiago, Chile: Sudamericana, 2004.

Joignant, Alfredo. Diccionario de la política chilena: momios, upelientos, operadores y encapuchados. Lugares comunes, lugares sociales y cocina política. Santiago, Chile: Random House Mondadori, 2011.

Lemebel, Pedro. "Entrevista de Lemebel a Bolaño". Radio Tierra. Diciembre 1999. https://www.youtube.com/watch?v=Ha5jbU2ojBU

Lafourcade, Enrique. Antología del nuevo cuento chileno. Santiago, Chile: Zig-Zag, 1954.

Lafourcade, Enrique. Salvador Allende. Barcelona: Grijalbo, 1973.

Lafourcade, Enrique. Tres terroristas. Barcelona: Pomaire, 1976.

Lafourcade, Enrique. Adiós al Führer. Barcelona: Bruguera, 1982.

Lafourcade, Enrique. Pepita de oro. Santiago, Chile: Zig-zag, 1990.

Lafourcade, Enrique. Mano bendita. Santiago, Chile: Planeta, 1993.

Lafourcade, Enrique. Animales literarios chilenos. Santiago, Chile: Sudamericana, 1996.

Lafourcade, Enrique Palomita blanca. Santiago, Chile: Zig-zag, 2007.

Lagos, Claudia. El diario de Agustín. Cinco estudios de casos sobre El Mercurio y los derechos humanos (1973-1190). Santiago, Chile: Lom, 2009.

León, Marco. "Gradual secularización de lo cotidiano". Historia de la Iglesia en Chile. Los caminos: la Iglesia y el Estado. Tomo III. Santiago, Chile: Universitaria, 2015. 481-536.

Madariaga, Ainara. Imaginarios vascos desde Chile. La construcción de imaginarios vascos en Chile durante el siglo XX. País Vasco: Universidad del País Vasco, 2005.

Medina, Juan. Derecho civil: Derecho de familia. Bogotá, Colombia: Editorial Universidad de Rosario, 2014.

Merino, Roberto. "Dos mundos". El Mercurio (Santiago, Chile), 3 Nov. 2008: 17.

Milos, Pedro. Memoria a 40 años. Chile 1970. El país en que triunfa Salvador Allende. Santiago, Chile: Ediciones Universidad Alberto Hurtado, 2013.

Mönckeberg, María. El imperio del Opus dei en Chile. Santiago, Chile: Penguin Random House, 2016.

Montesinos, Sonia. Madres y huachos. Alegoría del mestizaje chileno. Santiago, Chile: Catalonia, 2007.

Montes, Hugo. "La última novela de Enrique Lafourcade". El Mercurio (Santiago, Chile), 13 Nov. 1977: 3.

Pimentel, Luz Aurora. El espacio en la ficción. Buenos Aires, Argentina: Siglo veintiuno, 2001.

Politzer, Patricia. El libro de Lagos. Santiago, Chile: Ediciones B. Chile S.A, 1998.

Rojas, Wellingtone. "El Führer de Lafourcade". El diario Austral (Temuco, Chile) ,15 Nov. 1983: 2.

Sierra, Malú. "Enrique Lafourcade, escritor y despotricador". Historias de Paula. Antología de reportajes y entrevistas. Santiago, Chile: Catalonia, 2013. 77-86. 
Soler, Pablo. El enigma de los símbolos. México: Fondo de Cultura Económica, 2013.

Saulquin, Susana. Jeans: la Vigencia de un mito. Buenos Aires, Argentina: Nobuko, 2004.

Subercaseaux, Bernardo. Historia del libro en Chile: desde la Colonia hasta el Bicentenario. Santiago, Chile: Lom, 2010.

Valdivia, Verónica. Nacionales y gremialistas. El "parto" de la nueva derecha política chilena, 1964-1973. Santiago, Chile: Lom, 2008.

Valdivia, Verónica."Todos juntos seremos la historia: Venceremos". Unidad Popular y

Fuerzas Armadas”. Cuando hicimos historia. La experiencia de la Unidad Popular. Santiago, Chile: Lom, 2005. 177-206.

Vicencio, Tamara. "Prácticas barriales en un espacio multicultural". Rutas migrantes en Chile. Habitar, festejar. Santiago, Chile: Universidad Alberto Hurtado, 2015. 73-96.

Wessel, Günther. Los Allende: con ardiente paciencia un mundo mejor. Madrid: Tébar, 2004.

White, Hayden. "El texto histórico como artefacto literario y otros escritos". El texto histórico como artefacto literario. Barcelona: Paidós, 2003. 107-139.

Zaliasnik, Yael. Memoria inquieta. Santiago, Chile: Fondo de cultura económica, 2016. 